\title{
Successful Resuscitation from Cardiopulmonary Arrest: 5-FU Cardiotoxicity
}

\section{Yasuhiro Nakamura*, Masanari Kuwabara, Haruo Mitani, Minoru Ono and Sugao Ishiwata}

Department of Cardiology, Toranomon Hospital, Japan

\begin{abstract}
A 61-year-old man with 5-fluorouracil (5-FU) chemotherapy suffered a cardiopulmonary arrest (CPA). The electrocardiogram showed changes consistent with myocardial infarction only during CPA that was normalized 30 minutes after cardiopulmonary resuscitation. Coronary angiography showed no significant stenosis. We suspected the cause of CPA to be vasospastic angina due to 5-FU and administered Benidipine, Diltiazem, and Isosorbide mononitrate to prevent recurrence of vasospasm.
\end{abstract}

Keywords: 5-Fluorouracil; Cardiotoxicity; Chemotherapy; Cardiopulmonary arrest

\section{Introduction}

5-flourouracil (5-FU) is widely used as a chemotherapeutic agent, especially for gastroenterological cancer. It acts as a thymidylate synthase inhibitor. Cardiotoxicity is among the well-known toxic adverse effects of 5-FU. Reported cardiovascular events include chest pain, dyspnea, confusion, electrocardiographic (ECG) changes, vasospastic myocardial ischemia, myocardial infarction and sudden death. There are some reports regarding the association of 5-FU with vasospasm, but cardiopulmonary arrest (CPA) caused by 5 -FU induced vasospasm is rare. We present a case of CPA during 5-FU administration from which the patient recovered fully from desperate CPA, and a review of literature related to this is included.

\section{Case Report}

A 61-year-old man with esophageal carcinoma had undergone a subtotal esophagectomy with three-field lymphadenectomy following gastric tube esophagoplasty two months ago. Because the histological diagnosis was squamous cell carcinoma (pT3N2M0, p-Stage 3), the patient was started on an F-Ndp chemotherapy regimen (Nedaplatin 64 $\mathrm{mg} / \mathrm{m}^{2}$ day and 1,5-Fluorouracil (5-FU) $638 \mathrm{mg} / \mathrm{m}^{2}$ with continuous infusion over 120 hours). Other medical history included mild hypertension, which was well controlled by angiotensin receptor blocker, and IgA nephropathy that was treated by renal transplantation 12 years ago. On day six following the initiation of chemotherapy, the patient complained of discomfort and nausea. When the patient was referred to us, on presentation, the vital sign included consciousness of GCS E4V4M6, blood pressure of 53/36 $\mathrm{mmHg}$, heart rate of 60 beats per minute, respiration rate of 25 per minute, $\mathrm{SpO}_{2}$ of $100 \%$ in ambient air. Physical examination was normal except for cold extremities and diaphoresis. Before the patient lost consciousness, we performed blood examination, which revealed no significant abnormalities (Table 1). Gradually, the patient lost consciousness and went into a cardiopulmonary arrest (CPA). The electrocardiogram (ECG) revealed ST elevation in leads II, III, augmented vector foot (aVF), and V5-6 (Figure 1). Ultrasound cardiogram (UCG) showed diffuse hypokinesia and moderate pericardial effusion. Although we performed cardiopulmonary resuscitation with tracheal tube intubation, the ECG still showed pulseless electric activity. After 25 minutes continuous resuscitation, the ECG showed fine VF, and two shocks with direct current (DC) led to return of spontaneous circulation. (The laboratory profile after recovery: Table 2, the ECG: Figure 2) Coronary angiography and pulmonary arteriography did not show significant stenosis in the coronary arteries, and there was no defect in the pulmonary artery. To

\begin{tabular}{|c|c|}
\hline \multicolumn{2}{|c|}{ Chemical panel } \\
\hline TP & $6.4 \mathrm{~g} / \mathrm{dL}$ \\
\hline Alb & $4 \mathrm{~g} / \mathrm{dL}$ \\
\hline BUN & $57 \mathrm{mg} / \mathrm{dL}$ \\
\hline $\mathrm{Cr}$ & $0.96 \mathrm{mg} / \mathrm{dL}$ \\
\hline T-BIL & $1.1 \mathrm{mg} / \mathrm{dL}$ \\
\hline AST & $48 \mathrm{IU} / \mathrm{L}$ \\
\hline ALT & $59 \mathrm{IU} / \mathrm{L}$ \\
\hline $\mathrm{LDH}$ & $203 \mathrm{IU} / \mathrm{L}$ \\
\hline $\mathrm{CK}(\mathrm{MB})$ & $57(5.2) \mathrm{IU} / \mathrm{L}$ \\
\hline $\mathrm{Na}$ & $141 \mathrm{mEq} / \mathrm{L}$ \\
\hline K & $4 \mathrm{mEq} / \mathrm{L}$ \\
\hline $\mathrm{Cl}$ & $107 \mathrm{mEq} / \mathrm{L}$ \\
\hline $\mathrm{Ca}$ & $8.9 \mathrm{mg} / \mathrm{dlL}$ \\
\hline \multicolumn{2}{|c|}{ CBC } \\
\hline WBC & $8400 / \mu \mathrm{L}$ \\
\hline $\mathrm{Hb}$ & $15.4 \mathrm{~g} / \mathrm{dL}$ \\
\hline Plt & $257 \times 1000 / \mu \mathrm{L}$ \\
\hline \multicolumn{2}{|c|}{ Immune } \\
\hline CRP & $0.1 \mathrm{mg} / \mathrm{dL}$ \\
\hline \multicolumn{2}{|c|}{ ABG $\left(\mathrm{FiO}_{2}: 100 \%\right)$} \\
\hline $\mathrm{pH}$ & 7.60 \\
\hline $\mathrm{pO}_{2}$ & 89 Torr \\
\hline $\mathrm{pCO}_{2}$ & 12 Torr \\
\hline $\mathrm{HCO}_{3}$ & $11 \mathrm{mmol} / \mathrm{L}$ \\
\hline Lac & $4.6 \mathrm{mmol} / \mathrm{L}$ \\
\hline
\end{tabular}

Table 1: Laboratory profile before loss of consciousness.

prevent vasospastic angina, Nicorandil was administered continuously. Also, to protect brain function, we administered 0 Celsius degrees linger to keep body temperature under $34^{\circ} \mathrm{C}$ for initial 48 hours after resuscitation. During staying in ICU, the ECGs showed no significant change on ST-T and serum CK level remained within normal limits. UCG showed preserved contraction. On the 10th day of ICU stay when

*Corresponding authors: Yasuhiro Nakamura, Department of Cardiology, 2-2-2, Toranomon, Toranomon Hospital, Minatoku, Tokyo, Japan, E-mail: yasuhiro.n1112@gmail.com

Received May 15, 2017; Accepted May 27, 2017; Published May 30, 2017

Citation: Nakamura Y, Kuwabara M, Mitani H, Ono M, Ishiwata S (2017) Successful Resuscitation from Cardiopulmonary Arrest: 5-FU Cardiotoxicity. J Cardiovasc Dis Diagn 5: 280. doi: 10.4172/2329-9517.1000280

Copyright: (c) 2017 Nakamura Y, et al. This is an open-access article distributed under the terms of the Creative Commons Attribution License, which permits unrestricted use, distribution, and reproduction in any medium, provided the original author and source are credited. 
the patient was extubated, no sequels were confirmed except slight retrograde amnesia, which recovered completely with rehabilitation at discharge. After administration of Benidipine, Diltiazem, and Isosorbide mononitrate, the patient did not suffer any cardiac events, and discharged 44 days after CPA. For esophageal cancer, we considered no more chemotherapy and continued with best supportive care.

\section{Discussion}

In this report, we presented a case of CPA while chemotherapy

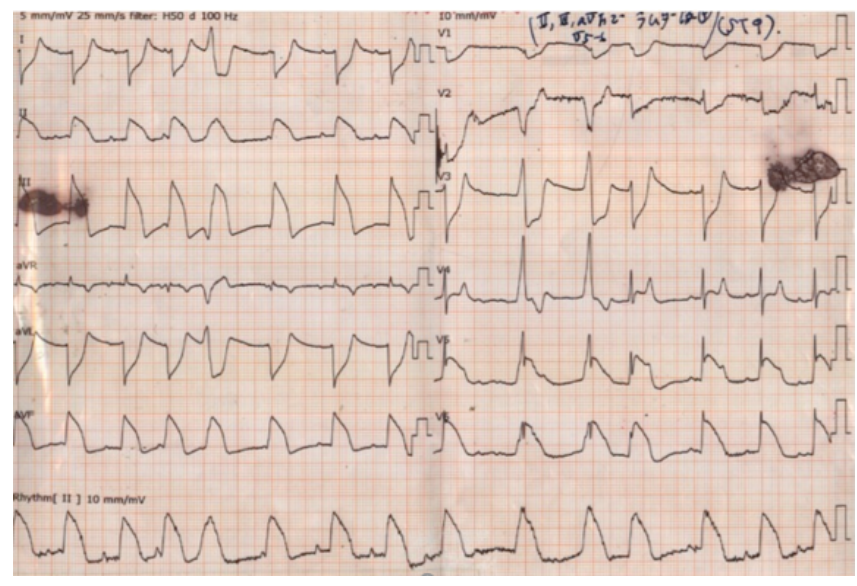

Figure 1: The electrocardiogram just after loss of consciousness showed ST elevation in leads III and aVF, and pericardial leads of V5-6 during cardiopulmonary arrest.

\begin{tabular}{|c|c|}
\hline \multicolumn{2}{|c|}{ Chemical panel } \\
\hline TP & $5.7 \mathrm{~g} / \mathrm{dL}$ \\
\hline Alb & $3.4 \mathrm{~g} / \mathrm{dL}$ \\
\hline BUN & $13 \mathrm{mg} / \mathrm{dL}$ \\
\hline $\mathrm{Cr}$ & $1.13 \mathrm{mg} / \mathrm{dL}$ \\
\hline T-BIL & $0.9 \mathrm{mg} / \mathrm{dL}$ \\
\hline AST & $171 \mathrm{IU} / \mathrm{L}$ \\
\hline ALT & $232 \mathrm{IU} / \mathrm{L}$ \\
\hline $\mathrm{LDH}$ & $483 \mathrm{IU} / \mathrm{L}$ \\
\hline $\mathrm{CK}(\mathrm{MB})$ & $92(8.7) \mathrm{IU} / \mathrm{L}$ \\
\hline $\mathrm{Na}$ & $141 \mathrm{mEq} / \mathrm{L}$ \\
\hline $\mathrm{K}$ & $4 \mathrm{mEq} / \mathrm{L}$ \\
\hline $\mathrm{Cl}$ & $104 \mathrm{mEq} / \mathrm{L}$ \\
\hline $\mathrm{Ca}$ & $9.3 \mathrm{mg} / \mathrm{dL}$ \\
\hline \multicolumn{2}{|c|}{ CBC } \\
\hline WBC & $17700 / \mu \mathrm{L}$ \\
\hline $\mathrm{Hb}$ & $14.9 \mathrm{~g} / \mathrm{dL}$ \\
\hline PIt & $19.575 / \mu \mathrm{L}$ \\
\hline \multicolumn{2}{|c|}{ Immune } \\
\hline CRP & $0.08 \mathrm{mg} / \mathrm{dL}$ \\
\hline \multicolumn{2}{|c|}{ Coagulation } \\
\hline PT-INR & 1.25 \\
\hline APTT & $49.9 \mathrm{sec}$ \\
\hline D-dimer & $8 \mu \mathrm{g} / \mathrm{mL}$ \\
\hline \multicolumn{2}{|c|}{ ABG $\left(\mathrm{FiO}_{2}: 100 \%\right)$} \\
\hline $\mathrm{pH}$ & 7.01 \\
\hline $\mathrm{pO}_{2}$ & 69 Torr \\
\hline $\mathrm{pCO}_{2}$ & 50 Torr \\
\hline $\mathrm{HCO}_{3}$ & $12 \mathrm{mmol} / \mathrm{L}$ \\
\hline Lac & $13.7 \mathrm{mmol} / \mathrm{L}$ \\
\hline
\end{tabular}

Table 2: Laboratory profile during cardiopulmonary arrest.

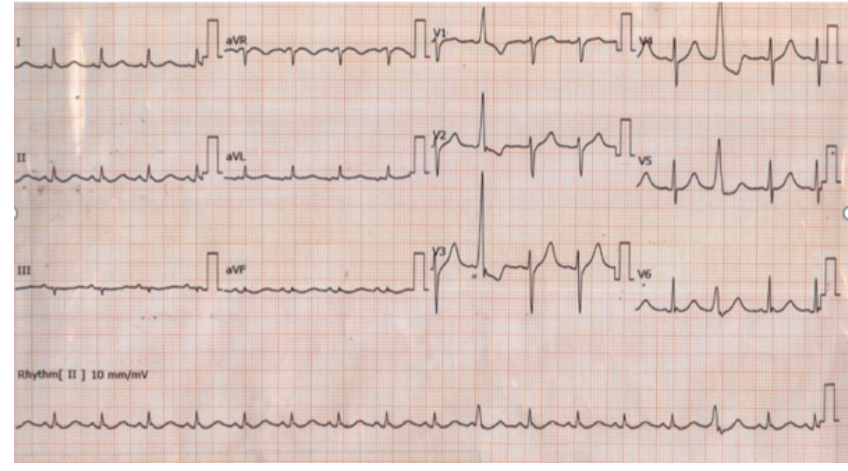

Figure 2: The electrocardiogram after automated external defibrillator showed normal sinus heart beat with PVC.

including 5-FU. Intensive care led favorable outcome as fully recovered from desperate CPA. In the beginning, the patient did not have cardiac comorbidities, and the only coronary risk factor was mild hypertension.

For about 50 years, 5 -FU has been used as a thymidylate synthase inhibitor for the treatment of cancer, especially for gastroenterological cancers. There are some well-known adverse effects of 5-FU and cardiotoxicity is one of them. Reported cardiovascular events include chest pain, dyspnea, confusion, ECG changes, vasospastic myocardial ischemia, myocardial infarction, and sudden death [1]. In terms of 5-FU induced cardiovascular toxicities, the incidence and mortality varies depending on the study. One study with more than 400 patients reveals that the estimates of the incidence of symptomatic cardiotoxicity is reported to be $1.2 \%$ to $4.3 \%$ and the frequency of sudden death during 5 -FU chemotherapy is around $0 \%$ to $0.5 \%$ [2].

In reviewing literature, 5-FU induced vasospastic angina is sporadically reported. Hence, we suspected the cause of CPA was vasospastic angina due to 5-FU administration, which was also suggested because the ECG showed changes consistent with myocardial infarction only during CPA and these return to normal; moreover, coronary angiography showed no significant stenosis.

The mechanism of these cardiovascular events by 5 -FU is not elucidated, but several probable causes and factors are discussed. One is that 5-FU may have deleterious effects on the endothelium. Many studies and case reports have been published about vasospasm due to toxic effects on the coronary endothelial intima [3,4]. Kosmas et al. reported that the toxicity becomes more pronounced about three days after the start of 5-FU administration by increased prostacyclin release [2]. On the other hand, de Forni et al. considered 5-FU might have deleterious effects on the myocytes because some patients with reduced ejection fraction and significant akinesia whose symptoms did not correspond to the segmental distribution of coronary lesions, which suggests direct drug toxicity or dug metabolite-mediated toxicity on the myocyte [5]. Another hypothesis is 5-FU may have caused changes in membrane potential. Matsubara et al. reported an excessive increase in the oxygen consumption and metabolite degeneration produced by the compound lead to the depletion of the high energy phosphate compound, which causes ECG change and chest symptom [6].

The manner of administration of 5-FU may also associate with the occurrence of cardiotoxicity. Continuous 5-FU infusion and/or combination therapy with cisplatin is associated with a higher incidence of cardiotoxicity [7]. Leucovorin plus continuous 5-FU infusion also increases the rate of cardiotoxicity compared with 5-FU alone [1]. 
Citation: Nakamura Y, Kuwabara M, Mitani H, Ono M, Ishiwata S (2017) Successful Resuscitation from Cardiopulmonary Arrest: 5-FU Cardiotoxicity. J Cardiovasc Dis Diagn 5: 280. doi: 10.4172/2329-9517.1000280

Page 3 of 3

Pharmacokinetics of 5-FU can be an important factor to the cardiotoxicity. Cicconi et al. reported that lack of dihydropyrimidine dehydrogenase (DPD), which is the first and exclusive step in fluoropyrimidines catabolism, increases the 5-FU concentration [8]. $30 \%$ to $60 \%$ of patients with 5-FU induced toxicities are associated with heterozygosity for a DPD point mutation [9]. Nakamura et al. reported that the serum dihydrogenated metabolite dihydrouracil (DHU)/uracil (U) ratio has a weakly significant, positive correlation with liver DPD activity ( $\mathrm{r}=0.44, \mathrm{p}=0.035)$, and can be utilized as a new index for the safety of the 5-FU treatment [10]. In this case, we examined DPD activity at discharge, and the results were U: $5.53 \mathrm{ng} / \mathrm{ml}$, DHU: $108 \mathrm{ng} /$ $\mathrm{ml}$, and DHU/U:19.5 (Normal range: U $7.67 \mathrm{ng} / \mathrm{ml}$ to $12.1 \mathrm{ng} / \mathrm{ml}$, DHU $70.4 \mathrm{ng} / \mathrm{ml}$ to $103 \mathrm{ng} / \mathrm{ml}, \mathrm{DHU} / \mathrm{U}$ 7.59-11.8). In this patient, we could not point out abnormality in DHU/U ratio.

Consequently, the utilization of brain hypothermia therapy protected the patient's cerebral function completely, and administration of Benidipine, Diltiazem, and Isosorbide mononitrate might prevent recurrence of vasospasm. Although 5-FU is widely used in chemotherapy for many kinds of cancers, the clinician should administer 5-FU including regimen to the patient in the appropriate institutes to deal with a cardiovascular emergency.

\section{Conclusion}

Here we presented a case of CPA with vasospasm, which was suspected to have been induced by 5-FU therapy. There are some reports about the association between 5-FU and vasospasm, but a case of CPA caused by 5-FU induced vasospasm is rare. Currently, the exact cause and mechanism of cardiotoxicity in cancer patients treated with 5-FU compounds remain unclear. Further investigations will have to be conducted to gain insight into this mechanism and ensures safer chemotherapy.

\section{References}

1. Freeman NJ, Costanza ME (1988) 5-Fluorouracil-associated cardiotoxicity. Cancer 61: 36-45.

2. Kosmas C, Kallistratos MS, Kopterides P, Syrios J, Skopelitis H, et al. (2008) Cardiotoxicity of fluoropyrimidines in different schedules of administration: A prospective study. J Cancer Res Clin Oncol 134: 75-82.

3. Tsibiribi P, Bui-Xuan C, Bui-Xuan B, Lombard-Bohas C, Duperret S, et al (2006) Cardiac lesions induced by 5 -fluorouracil in the rabbit. Hum Exp Toxicol 25: 305-309.

4. Cwikiel M, Zhang B, Eskilsson J, Wieslander JB, Albertsson M (1995) The influence of 5 -fluorouracil on the endothelium in small arteries. An electron microscopic study in rabbits. Scanning microscopy 9: 561-576.

5. De Forni M, Malet-Martino MC, Jaillais P, Shubinski RE, Bachaud JM, et al. (1992) Cardiotoxicity of high-dose continuous infusion fluorouracil: A prospective clinical study. J Clin Oncol 10: 1795-1801.

6. Matsubara I, Kamiya J, Imai S (1980) Cardiotoxic effects of 5-fluorouracil in the guinea pig. Jpn J Pharmacol 30: 871-879.

7. Khan MA, Masood N, Husain N, Ahmad B, Aziz T, et al. (2012) A retrospective study of cardiotoxicities induced by 5 -fluouracil (5-FU) and 5-FU based chemotherapy regimens in Pakistani adult cancer patients at Shaukat Khanum memorial cancer hospital \& research center. J Pak Med Assoc 62: 430-434.

8. Ezzeldin H, Diasio R (2004) Dihydropyrimidine dehydrogenase deficiency, a pharmacogenetic syndrome associated with potentially life-threatening toxicity following 5-fluorouracil administration. Clin Colorect Cancer 4: 181-189.

9. van Kuilenburg $A B$, Haasjes J, Richel DJ, Zoetekouw L, Van Lenthe $H$, et al. (2000) Clinical implications of dihydropyrimidine dehydrogenase (DPD) deficiency in patients with severe 5-fluorouracil-associated toxicity: Identification of new mutations in the DPD gene. Clin Cancer Res 6: 4705-4712.

10. Nakamura A, Kikuchi K, Ohishi T, Masuike T (2004) Assay method for uracil, dihydrouracil, 5-fluorouracil and 5-fluoro-5, 6-dihydrouracil by high-performance liquid chromatography. Gan to kagaku ryoho. Cancer chemother 31: 381-386. 